Arq. Bras. Med. Vet. Zootec., v.56, n.2, p.193-201, 2004

\title{
Desempenho e rendimento de carcaça de bezerros alimentados com colostro fermentado, associado ao óleo de soja e zeranol
}

[Performance and carcass yield of calves fed with fermented colostrum, associated with soybean oil and zeranol]

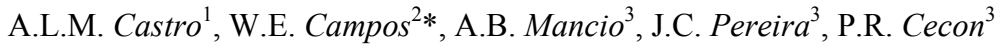 \\ ${ }^{1}$ Faculdades Integradas do Planalto Central - Valparaíso, GO \\ ${ }^{2}$ Doutorando em Nutrição Animal - Universidade Federal de Minas Gerais - Belo Horizonte, MG \\ ${ }^{3}$ Universidade Federal de Viçosa - Viçosa, MG
}

\begin{abstract}
RESUMO
Utilizaram-se 40 bezerros Holandês $\times$ Zebu distribuídos em oito tratamentos (T): leite integral (1); leite integral com óleo de soja (2); leite integral e zeranol (3); leite integral com óleo de soja e zeranol (4); colostro fermentado (5); colostro fermentado com óleo de soja (6); colostro fermentado e zeranol (7); e colostro fermentado com óleo de soja e zeranol (8) com o objetivo de avaliar o consumo de alimentos, o crescimento e a conversão alimentar de animais entre o $15^{\circ}$ e o $60^{\circ}$ dia de vida. Diariamente, foram fornecidos $1,5 \mathrm{~kg}$ de concentrado contendo $23 \%$ de proteína bruta, feno de tifton (Cynodon dactylon) à vontade e três litros de leite ou colostro fermentado. $\mathrm{O}$ colostro fermentado proporcionou melhores resultados de peso corporal e ganho de peso quando comparado ao leite integral, mas semelhantes aos resultados com zeranol. Também promoveu maior ingestão de matéria seca em relação ao leite integral, o que resultou em desempenhos semelhantes para esses dois tipos de alimento. Não houve diferenças entre os tratamentos quanto aos componentes não-integrantes da carcaça. O tratamento com leite e zeranol resultou em maior peso de carne industrial e o com óleo de soja aumentou a proporção de gordura interna. O colostro fermentado é uma boa opção para a recria de machos leiteiros e o efeito do zeranol sobre o ganho de peso é dependente da dieta dos animais.
\end{abstract}

Palavras-chave: bezerro, alimentação, colostro, zeranol, carcaça

\begin{abstract}
Forty Holstein $\times$ Zebu calves from the 15th to the 60th day of age, were divided in eight treatments $(T)$ : whole milk (1); whole milk with soybean oil (2); whole milk with zeranol (3); whole milk with soybean oil and zeranol (4); fermented colostrum (5); fermented colostrum with soybean oil (6); fermented colostrums with zeranol (7); and fermented colostrum with soybean oil and zeranol (8) to measure feed intake, growth and feed conversion. Animals were fed daily on $1.5 \mathrm{~kg}$ of concentrate containing $23 \%$ crude protein, ad libitum tifton hay (Cynodon dactylon) and three liters of milk or fermented colostrum. Calves fed on fermented colostrum showed higher body weight and weight gain than those receiving milk and similar performance to those treated with zeranol. Animals fed on fermented colostrum had higher dry matter intake in comparison with animals fed on milk. Both groups of animals showed similar growth. No differences for non-integrant carcass compounds where found, however, calves fed on milk and receiving zeranol showed higher industrial meat yield. Diet based on soybean oil increased the
\end{abstract}

Trabalho financiado pela FAPEMIG.

Recebido para publicação em 30 de abril de 2003

Recebido para publicação, após modificações, em 18 de março de 2004

*Endereço para correspondência:

Av. Contagem, 1840, Bairro: Santa Inês

31080-000 - Belo Horizonte, MG

E-mail: wecampos@hotmail.com 
proportion of internal fat. Fermented colostrum showed to be an alternative feed for growing male dairy calves and the effect of zeranol on weight gain depends on the diet.

Keywords: calve, feeding, colostrum, zeranol, carcass

\section{INTRODUÇÃO}

A utilização de animais provenientes de rebanhos leiteiros para produção de carne é realidade em alguns países (A carne..., 2003), entretanto, a maior parte dos 7,5 milhões de bezerros leiteiros nascidos por ano no país é descartada. Tais animais poderiam ser destinados ao abate, fornecendo um alimento nutritivo, tenro e com baixo teor de colesterol (Ribeiro, 2001a). O custo de criação desses animais, principalmente na fase de aleitamento, é o principal fator limitante (Caldas, 2003), sendo aconselhável a substituição, o mais rápido possível, do leite por outros alimentos líquidos (Alves, Lizieire, 2001) ou sólidos (Teixeira, 2000).

Entre os alimentos líquidos destaca-se a utilização do excesso de colostro produzido na propriedade, o qual pode ser utilizado na criação de machos leiteiros, reduzindo os custos de criação. O leite apresenta, com base na matéria seca, teor de gordura em torno de $31 \%$; no colostro a concentração de lipídeo é menor, podendo ocasionar deficit energético nos animais, caso a deficiência não seja minimizada (Blum, Hammon, 2000).

O armazenamento do colostro pode ser na forma refrigerada ou congelada (Argüello et al., 2003), quando se deseja preservar as imunoglobulinas (Borges et al., 2001), ou fermentada, quando se quer conservar o valor nutricional. Essa última opção é mais utilizada para grandes volumes (Morril, 1992; Matos, 1996).

Este experimento teve como objetivo avaliar o desempenho, desenvolvimento dos órgãos internos e características da carcaça de bezerros leiteiros alimentados com colostro fermentado, associado ao óleo de soja com ou sem a utilização de promotor de crescimento.

\section{MATERIAL E MÉTODOS}

Foram utilizados 40 bezerros mestiços (Holandês-Gir) os quais permaneceram as primeiras 24horas de vida com a mãe. Após esse período foram identificados, vermífugados e receberam $5 \mathrm{ml}$ de complexo vitamínico ADE injetável. Os tratamentos experimentais foram constituídos de quatro dietas líquidas, com ou sem a aplicação do zeranol, administradas do $15^{\circ}$ ao $60^{\circ}$ dia de vida dos animais. Dessa forma, oito tratamentos $(\mathrm{T})$ foram obtidos: T1 - leite integral; T2 - leite integral com óleo de soja; T3 - leite integral e zeranol; T4 - leite integral com óleo de soja e zeranol; T5 - colostro fermentado; T6 colostro fermentado com óleo de soja; T7 colostro fermentado e zeranol ; e T8 - colostro fermentado com óleo de soja e zeranol. Os animais foram também pesados semanalmente, mensurados na altura da cernelha e avaliados quanto ao comprimento torácico.

Foram fornecidos três litros de lácteos diariamente no período da tarde. O concentrado inicial, contendo $23 \%$ de proteína bruta (Tab. 1), foi fornecido em quantidades crescentes, até atingir o limite máximo de $1,5 \mathrm{~kg}$ por dia. $\mathrm{O}$ feno de tifton (Cynodon dactylon) foi fornecido à vontade. A análise bromatológica dos alimentos é apresentada na Tab. 2.

Tabela 1. Composição dos ingredientes do concentrado fornecido aos animais no período experimental

\begin{tabular}{lc}
\hline Ingrediente & $\%$ \\
\hline Fubá de milho & 56,5 \\
Farelo de soja & 30,0 \\
Farelo de trigo & 10,0 \\
Farinha de osso & 1,0 \\
Fosfato bicálcico & 1,5 \\
Premix mineral* & 1,0 \\
\hline * Formulação: sulfato de zinco (50\%), sulfato de cobre \\
(42\%), sulfato de cobalto $(2,7 \%)$, selenito de sódio $(2,7 \%)$ e \\
iodeto de potássio $(2,7 \%)$.
\end{tabular}


Desempenho e rendimento de carcaça de bezerros...

Tabela 2. Teores de matéria seca (MS), proteína bruta (PB), extrato etéreo (EE), cinzas (C), carboidratos totais (CHOT), fibra em detergente neutro (FDN), carboidratos não-estruturais (CNE) e fibra em detergente ácido (FDA) (\% da MS) do concentrado e do volumoso

\begin{tabular}{lcccccccc}
\hline Ingrediente & MS & PB & EE & C & CHOT & FDN & CNE & FDA \\
\hline Concentrado & 87,32 & 23,21 & 2,92 & 6,92 & 66,95 & 15,08 & 51,87 & 6,8 \\
Feno & 91,44 & 10,34 & 1,37 & 8,69 & 79,60 & 78,52 & 1,08 & 35,68 \\
\hline
\end{tabular}

O colostro obtido nas primeiras ordenhas de vacas doadoras foi armazenado em tambores plásticos. Foi necessária uma semana para que o processo fermentativo se efetivasse, sendo permitido o máximo de 28 dias de fermentação a fim de evitar a acidez excessiva e a possibilidade de contaminação por microrganismos indesejáveis, o que poderia comprometer a aceitação do produto. Todo colostro fresco era então misturado ao colostro já fermentado e servido aos bezerros.
Os animais dos tratamentos 2, 4, 6 e 8 receberam, adicionados à dieta líquida, $45 \mathrm{ml}$ de óleo degomado de soja e $2,5 \mathrm{ml}$ de emulsificante à base de lecitina de soja. Nas dietas líquidas contendo colostro fermentado foram acrescentados $25 \mathrm{~g}$ de bicarbonato de sódio. A análise bromatológica da dieta líquida encontrase na Tab. 3 .

Tabela 3. Teores de matéria seca (MS), proteína bruta (PB), energia bruta (EB) e cinzas (C) (\% MS) e gordura total $(\mathrm{GT})(\% \mathrm{MN})$ dos alimentos líquidos utilizados no experimento

\begin{tabular}{lccccc}
\hline Ingrediente & MS & PB & EB & C & GT \\
$(\%)$ & $(\%)$ & 29 cal/kg) & $(\%)$ & $(\%)$ \\
\hline Leite & 10,5 & 27,0 & 29,7 & 6,4 & 3,1 \\
Leite com óleo & 10,6 & 29,6 & 35,1 & 6,9 & 4,2 \\
Colostro fermentado & 8,9 & 48,8 & 30,0 & 13,2 & 1,1 \\
Colostro fermentado com óleo & 9,4 & 49,4 & 31,7 & 11,5 & 1,3 \\
\hline
\end{tabular}

Os dados referentes ao fornecimento e sobras da dieta sólida foram computados diariamente para avaliação do consumo de matéria seca. Foram coletadas amostras do leite, colostro fermentado, concentrado e feno para análise bromatológica desses elementos. Semanalmente, após jejum de 16 horas, as animais formam pesados, mensurados quando ao comprimento torácico e altura de cernelha.

Aos 15 dias de idade, no início do experimento, os animais foram implantados com um pellet contendo de $36 \mathrm{mg}$ de zeranol. A aplicação foi realizada na base do pavilhão auricular direito nos animais dos tratamentos 3, 4, 7 e 8 .

Aos 60 dias de idade foram submetidos a jejum de 16 horas, pesados, medidos e abatidos. Foram computados os dados referentes à carcaça, membros, cabeça, couro, rúmen-retículo, omaso, abomaso, intestino delgado, intestino grosso, gordura interna, fígado, coração, rins, baço, pulmões, língua, sangue, mesentério, carne industrial, cauda e o peso em conjunto do esôfago, traquéia e aparelho reprodutor.
As meias-carcaças foram levadas à câmara fria, onde permaneceram por 18 horas, a $-5^{\circ} \mathrm{C}$, para a determinação do peso da carcaça fria.

O comprimento de carcaça foi mensurado da porção mediana anterior da primeira costela até o ponto mediano da curvatura do osso púbis. Um fragmento envolvendo a seção transversal entre a $9^{\mathrm{a}}, 10^{\mathrm{a}}$ e $11^{\mathrm{a}}$ costelas foi retirado para determinação das proporções de osso, músculo e tecido adiposo, segundo metodologia descrita por Hankins e Howe (1946). Foi medida a área de olho de lombo do músculo Longissimus dorsi na altura da $12^{\mathrm{a}}$ costela.

Nas análises estatísticas envolvendo os oito tratamentos, com cinco repetições, utilizaram-se os seguintes procedimentos: para as variáveis peso, consumo de concentrado, consumo de matéria seca, consumo de proteína bruta, comprimento torácico e altura de cernelha foi utilizado um esquema em parcelas subdivididas, em que as parcelas corresponderam aos tratamentos e as subparcelas as idades $(15,22$, 
29, 36, 43, 50 e 57 dias), seguindo um delineamento inteiramente ao acaso.

Para as variáveis ganho de peso, ganho médio diário e características de carcaça utilizou-se esquema fatorial $2 \times 2 \times 2$ (leite e colostro; dois níveis de óleo e aplicação ou não de zeranol), segundo um delineamento inteiramente ao acaso, com cinco repetições por tratamento.

As médias dos valores qualitativos foram comparadas utilizando os testes de Fisher (1 e $5 \%$ ) e Student Neuman Keulls (5\%).

Os dados foram avaliados utilizando-se o programa SAEG (Sistema..., 1997).

\section{RESULTADOS E DISCUSSÃO}

A aceitação do colostro fermentado foi boa por todos os animais submetidos aos tratamentos. Parte da literatura consultada (Foley, Otterby, 1978; Morril, 1992) mostrou que os animais rejeitaram tal alimento. A adição de bicarbonato de sódio ao colostro fermentado, segundo Lizieire e Campos (1986), pode ter sido um dos fatores responsáveis pelo alto grau de aceitabilidade.

Considerando-se as características físicoquímicas do óleo degomado e da lecitina de soja, não foi possível obter perfeita homogeneização desses componentes com o colostro fermentado, pois a lecitina de soja foi administrada na forma líquida, sendo seu efeito homogeneizante melhor observado quando adicionada em misturas na forma de pó (Campos et al., 1985; Lucci, 1989).

Queda acentuada de pêlos nas regiões peribucal e perianal foi observada nos animais dos tratamentos com colostro fermentado. A causa dessa alopecia pode estar relacionada ao poder abrasivo do colostro fermentado naturalmente, devido à presença de compostos fenólicos, ácidos graxos e ao elevado grau de acidez (Campos, Lizieire, 1995).

O consumo de matéria seca encontra-se na Tab. 4. Os animais dos tratamentos com colostro fermentado apresentaram maior consumo, atribuído à maior ingestão de concentrado. Tal fato pode estar relacionado à deficiência energética do colostro.

Tabela 4. Consumo médio diário $(\mathrm{kg})$ de matéria seca total segundo os tratamentos e o número de dias de experimento

\begin{tabular}{lcccccccc}
\hline \multirow{2}{*}{ Tratamento } & \multicolumn{7}{c}{ Tempo (dias) } \\
\cline { 2 - 8 } & 15 & 22 & 29 & 36 & 43 & 50 & 57 & Média \\
\hline T1 & $0,365 \mathrm{c}$ & $0,430 \mathrm{c}$ & $0,469 \mathrm{f}$ & $0,614 \mathrm{~h}$ & $0,645 \mathrm{~g}$ & $0,719 \mathrm{~h}$ & $0,725 \mathrm{~g}$ & 0,566 \\
T2 & $0,345 \mathrm{f}$ & $0,389 \mathrm{~g}$ & $0,465 \mathrm{~g}$ & $0,644 \mathrm{f}$ & $0,641 \mathrm{~h}$ & $0,760 \mathrm{~g}$ & $0,689 \mathrm{~h}$ & 0,562 \\
T3 & $0,366 \mathrm{~b}$ & $0,379 \mathrm{~h}$ & $0,495 \mathrm{e}$ & $0,622 \mathrm{~g}$ & $0,729 \mathrm{f}$ & $0,978 \mathrm{~d}$ & $1,008 \mathrm{~d}$ & 0,654 \\
T4 & $0,363 \mathrm{~d}$ & $0,404 \mathrm{~d}$ & $0,444 \mathrm{~h}$ & $0,684 \mathrm{~d}$ & $0,809 \mathrm{~d}$ & $0,975 \mathrm{e}$ & $0,818 \mathrm{e}$ & 0,642 \\
T5 & $0,362 \mathrm{e}$ & $0,399 \mathrm{e}$ & $0,563 \mathrm{c}$ & $0,808 \mathrm{~b}$ & $1,089 \mathrm{~b}$ & $1,372 \mathrm{~b}$ & $1,067 \mathrm{~b}$ & 0,809 \\
T6 & $0,428 \mathrm{a}$ & $0,543 \mathrm{a}$ & $0,704 \mathrm{a}$ & $0,948 \mathrm{a}$ & $1,230 \mathrm{a}$ & $1,436 \mathrm{a}$ & $1,072 \mathrm{a}$ & 0,866 \\
T7 & $0,340 \mathrm{~h}$ & $0,394 \mathrm{f}$ & $0,541 \mathrm{~d}$ & $0,648 \mathrm{e}$ & $0,768 \mathrm{e}$ & $0,947 \mathrm{f}$ & $0,746 \mathrm{f}$ & 0,626 \\
T8 & $0,343 \mathrm{~g}$ & $0,454 \mathrm{a}$ & $0,606 \mathrm{~b}$ & $0,785 \mathrm{c}$ & $0,919 \mathrm{c}$ & $1,131 \mathrm{c}$ & $1,011 \mathrm{c}$ & 0,750 \\
\hline
\end{tabular}

T1 - leite integral; T2 - leite integral com óleo de soja; T3 - leite integral e zeranol; T4 - leite integral com óleo de soja e zeranol; T5 - colostro fermentado; T6 - colostro fermentado com óleo de soja; T7 - colostro fermentado e zeranol ; e T8 - colostro fermentado com óleo de soja e zeranol

Valores seguidos por letras distintas na coluna diferem entre si pelo teste $\mathrm{SNK}(\mathrm{P}<0,05)$.

Houve interação entre a dieta líquida e o promotor de crescimento para os valores de consumo total de matéria seca (Tab. 5).

Animais alimentados com colostro apresentaram $24,9 \%$ de aumento no consumo em relação aos que recebiam leite, entretanto ocorreu interação negativa quando o zeranol foi aplicado nos animais que recebiam colostro.
Tabela 5. Consumo de matéria seca $(\mathrm{kg})$, de acordo com a dieta líquida e o promotor de crescimento

\begin{tabular}{lcc}
\hline Dieta & $\begin{array}{c}\text { Sem } \\
\text { zeranol }\end{array}$ & $\begin{array}{c}\text { Com } \\
\text { zeranol }\end{array}$ \\
\hline Leite & $26,66 \mathrm{Ab}$ & $31,05 \mathrm{Aa}$ \\
Colostro fermentado & $40,32 \mathrm{Aa}$ & $32,29 \mathrm{Ba}$ \\
\hline Valores seguidos por letras distintas maiúsculas na linha e
\end{tabular}

minúsculas na coluna diferem entre si pelo teste $\mathrm{F}(\mathrm{P}<0,05)$. 
A partir do $36^{\circ}$ dia, a ingestão protéica nos animais alimentados com leite integral não foi suficiente para manter taxas de ganho diário superiores a $500 \mathrm{~g}$, o que não ocorreu nos alimentados com colostro fermentado, que tiveram à disposição maior quantidade de proteína bruta. Todavia, o ganho médio diário dos animais nos tratamentos 1 e $2(0,389 \mathrm{~kg})$ e 7 e $8(0,476 \mathrm{~kg})$ não foi satisfatório como os apresentados pelos tratamentos 5 e $6(0,494 \mathrm{~kg})$ e 3 e $4(0,537 \mathrm{~kg})$. Esses resultados indicam que, apesar de ingerirem quantidades diárias insuficientes de proteína, os animais dos tratamentos 3 e 4 apresentaram ganhos médios diários adequados, graças ao melhor aproveitamento protéico que, provavelmente, pode ser atribuído à ação do zeranol. Segundo Hall (1977), Brown (1984) e Rosa (1988), esse agente anabolizante promove maior taxa de absorção dos alimentos e melhor aproveitamento dos nutrientes disponíveis no sangue, graças ao estímulo do hormônio do crescimento. Esse fato pode ser comprovado pelos maiores índices de eficiência alimentar apresentados pelos bezerros tratados com promotor de crescimento $(0,71 \times 0,60)$.

O ganho médio diário dos bezerros foi influenciado pela interação dieta líquida versus promotor de crescimento (Tab. 6). Animais tratados com leite e zeranol apresentaram ganhos médios diários $37,8 \%$ superiores aos tratados com leite sem o anabolizante.

Tabela 6. Ganho médio diário $(\mathrm{kg})$ de bezerros, de acordo com a dieta líquida e o promotor de crescimento.

\begin{tabular}{lcc}
\hline Dieta & Sem zeranol & Com zeranol \\
\hline Leite & $0,389 \mathrm{Ba}$ & $0,537 \mathrm{Aa}$ \\
Colostro fermentado & $0,494 \mathrm{Aa}$ & $0,476 \mathrm{Aa}$ \\
\hline \multicolumn{2}{l}{ Valores seguidos por letras distintas maiúsculas na linha e } \\
minúsculas na coluna diferem entre si pelo teste $\mathrm{F}(\mathrm{P}<0,05)$.
\end{tabular}

Não houve diferença de ganho de peso entre animais que consumiram colostro fermentado tratado ou não com zeranol. Os valores observados são condizentes com os sugeridos por Lucci (1989) para animais mestiços, criados com dieta líquida e mistura iniciadora.

A média de ganho, 0,494 kg/animal/dia, obtida pelos animais que ingeriram colostro fermentado foi superior aos valores obtidos por Jenny et al.
(1984), Lizieire e Campos (1986) e Lucci (1989), que encontraram ganhos de 0,28 a $0,45 \mathrm{~kg} / \mathrm{animal} / \mathrm{dia}$. Estes resultados indicam boa eficiência de utilização do colostro fermentado na fase de aleitamento dos bezerros, uma vez que $\mathrm{o}$ produto forneceu nutrientes suficientes para permitir taxas de crescimento satisfatórias.

Não houve diferença entre tratamentos quanto a altura de cernelha. A média de $80,3 \mathrm{~cm}$ foi superior à encontrada por Rocha (1997), 78,2cm, para bezerros ao desaleitamento. Somente a utilização do colostro fermentado foi suficiente para garantir boa taxa de crescimento, uma que vez a mensuração da altura de cernelha apresenta correlação positiva com o desenvolvimento da estrutura óssea do animal (Signoretti, 1994).

O estudo do comprimento torácico dos bezerros, cuja média final foi de $88,2 \pm 4,2 \mathrm{~cm}$, não revelou diferenças entre os tratamentos.

A eficiência alimentar foi influenciada $(\mathrm{P}<0,01)$ pelos tratamentos. Para cada quilo de ganho de peso, foi necessário consumir $0,60 \mathrm{~kg}$ e $0,71 \mathrm{~kg}$ de matéria seca para os animais tratados com leite integral e com colostro fermentado, respectivamente, indicando que a dieta líquida tradicional possibilitou melhor aproveitamento da matéria seca ingerida.

Apesar de os animais submetidos ao colostro fermentado terem apresentado resultado inferior frente ao tratamento com leite integral, foram obtidos valores superiores aos encontrados por Rindisig (1976), 0,56, Campos et al. (1986), 0,47, e Lizieire e Campos (1986), 0,39.

Embora o colostro tenha diversos fatores que diminuem a incidência de diarréias (Uruakpa et al., 2002), dietas com colostro fermentado resultaram em quadros diarréicos que, possivelmente, contribuíram para o menor aproveitamento da matéria seca ingerida. Segundo Plog et al. (1974), a diarréia resultante da ingestão de colostro pode ser atribuída a alguns fatores antinutricionais formados no processo fermentativo.

A utilização do promotor de crescimento resultou em maior eficiência na conversão de matéria seca, aspecto já observado por Egan (1993) e Rosa (1988). Esse melhor índice pode ser justificado pelo aumento da concentração 
plasmática do hormônio do crescimento e da insulina parecida com o fator de crescimento, em resposta à aplicação do zeranol, conforme salientaram Thomas et al. (2000).

Não houve diferença entre tratamentos quanto à área de olho de lombo. A média geral foi de $15,3 \pm 25,8 \mathrm{~cm}^{2}$. Isso indica desenvolvimento muscular semelhante entre os animais, uma vez que a área de olho de lombo é normalmente considerada um indicador de desenvolvimento muscular (Ribeiro et al., 2001a). Foram verificadas diferenças para peso das carcaças quente e fria no estudo da interação entre dieta líquida e zeranol (Tab. 7).

Tabela 7. Peso (kg) da carcaça quente (PCQ) e da carcaça fria (PCF) de bezerros de acordo com a dieta líquida e o promotor de crescimento

\begin{tabular}{lccccc}
\hline \multirow{2}{*}{ Dieta } & \multicolumn{2}{c}{ PCQ } & & \multicolumn{2}{c}{ PCF } \\
\cline { 2 - 3 } \cline { 5 - 6 } & Sem zeranol & Com zeranol & & Sem zeranol & Com zeranol \\
\hline Leite & $32,6 \mathrm{Aa}$ & $36,1 \mathrm{Aa}$ & & $31,3 \mathrm{Aa}$ & $34,9 \mathrm{Aa}$ \\
Colostro fermentado & $34,2 \mathrm{Aa}$ & $30,3 \mathrm{Ab}$ & & $33,0 \mathrm{Aa}$ & \\
\hline
\end{tabular}

Valores seguidos por letras distintas maiúsculas na linha e minúsculas na coluna, para cada variável, diferem entre si pelo teste $\mathrm{F}$ $(\mathrm{P}<0,05)$.

Quando se utilizou zeranol os animais que receberam colostro apresentaram menor peso da carcaça em relação aos que receberam leite. Isto sugere interação negativa entre colostro e zeranol.

A redução do peso da carcaça atribuída à refrigeração foi de $3,5 \%$ e $3,7 \%$ para os animais que receberam ou não zeranol, respectivamente. Esses valores indicam que o zeranol não promoveu aumento de perda de água da carcaça, não confirmando os resultados de Hall (1977), que sugeriu maior perda de água durante o resfriamento de carcaças de animais tratados com zeranol, fato esperado graças à promoção do anabolismo protéico.

Verificou-se maior rendimento de carcaça para animais alimentados com leite $(54,2 \%)$ do que para os alimentados com colostro $(51,7 \%)$, e não foi observado efeito da aplicação do zeranol sobre essa característica. Apesar de não ter influenciado a composição da carcaça, a substituição de leite pelo colostro associado ao zeranol resultou em diminuição do crescimento, quando se avaliou o comprimento da carcaça (Tab. 8).

Tabela 8. Comprimento de carcaça $(\mathrm{cm})$ de bezerros, de acordo com a dieta líquida e o promotor de crescimento

\begin{tabular}{lcc}
\hline Dieta & Sem zeranol & Com zeranol \\
\hline Leite & $66,4 \mathrm{Aa}$ & $68,3 \mathrm{Aa}$ \\
Colostro fermentado & $68,6 \mathrm{Aa}$ & $65,0 \mathrm{Bb}$ \\
\hline \multicolumn{2}{l}{ Valores seguidos por letras distintas maiúsculas na linha e }
\end{tabular}

minúsculas na coluna diferem entre si pelo teste $\mathrm{F}(\mathrm{P}<0,05)$.
Observou-se diferença entre tratamentos quanto à proporção de ossos e de gordura na carcaça (Tab. 9). Srinivasan et al. (1998) não verificaram alteração da concentração de gordura na carcaça de animais implantados com zeranol, entretanto, ao avaliarem o perfil de ácidos graxos na gordura do músculo semimembranoso, verificaram alteração na sua composição. Não foi observado efeito do tratamento sobre a proporção de músculos na carcaça. A média geral, 66,5\%, para os dois tratamentos, confirma os resultados obtidos por Narro et al. (2003), isto é, não há alteração no teor de proteína da carcaça de animais suplementados com zeranol.

Tabela 9. Proporção de ossos e de gordura(\%) de bezerros de acordo com a dieta líquida

\begin{tabular}{lcc}
\hline Dieta & $\begin{array}{c}\text { Proporção } \\
\text { de ossos }\end{array}$ & $\begin{array}{c}\text { Proporção } \\
\text { de gordura }\end{array}$ \\
\hline Leite & $22,9 \mathrm{~A}$ & $9,7 \mathrm{~A}$ \\
Colostro fermentado & $21,4 \mathrm{~B}$ & $8,3 \mathrm{~B}$ \\
\hline
\end{tabular}

Valores seguidos por letras distintas na coluna diferem entre si pelo teste $\mathrm{F}(\mathrm{P}<0,05)$.

A dieta líquida contendo colostro conduziu a resultados inferiores quanto à proporção de ossos e gordura na carcaça dos bezerros, mas isto não comprometeu a taxa de crescimento, nem a estrutura física dos animais.

A menor proporção de tecido adiposo para os animais tratados com colostro fermentado pode ser explicada pela sua deficiência energética (Lucci, 1989; Campos, 1994). 
Não foram observadas diferenças entre tratamentos quanto aos pesos do baço, coração, fígado, pulmões, rins e língua.
O zeranol promoveu aumento do peso do rúmenretículo quando associado à dieta contendo leite $(+24,4 \%)($ Tab. 10).

Tabela 10. Peso (g) do rúmen-retículo e do intestino delgado de bezerros de acordo com a dieta líquida e o promotor de crescimento

\begin{tabular}{lcccc}
\hline \multirow{2}{*}{ Dieta líquida } & \multicolumn{2}{c}{ Rúmen-retículo } & \multicolumn{2}{c}{ Intestino delgado } \\
\cline { 2 - 4 } & Sem zeranol & Com zeranol & Sem zeranol & Com zeranol \\
\hline Leite & $639 \mathrm{Bb}$ & $795 \mathrm{Aa}$ & $1793 \mathrm{Aa}$ & $2047 \mathrm{Aa}$ \\
Colostro fermentado & $954 \mathrm{Aa}$ & $785 \mathrm{Ba}$ & $2076 \mathrm{Aa}$ & $1695 \mathrm{Bb}$ \\
\hline Valores seguidos por letras distintas & maiúsculas na linha e minúsculas na coluna, para cada variável, diferem entre si pelo teste $\mathrm{F}$
\end{tabular}
$(\mathrm{P}<0,01)$.

O peso do rúmen-retículo foi maior nos animais não implantados com zeranol tratados com colostro fermentado em relação aos não implantados que receberam leite. Isso se deveu ao maior consumo de concentrado, capaz de acelerar o processo de transformação do rúmen (Lucci, 1989). Segundo Church (1993), o tamanho do rúmen está relacionado com sua capacidade funcional, portanto, o maior peso pode estar relacionado com a sua transformação em estrutura funcional. Este resultado indica que os bezerros tratados com colostro, possivelmente, poderiam ser desmamados mais cedo, pois já estariam aptos a transformar alimentos vegetais em nutrientes.

Não foi observado efeito dos tratamentos sobre o peso do omaso, intestino grosso e conjunto esôfago, traquéia e aparelho reprodutor, cujas médias gerais foram: $185 \pm 18,2, \quad 706 \pm 21,1$ e $855 \mathrm{~g} \pm 27,5 \mathrm{~g}$, respectivamente.

Quanto ao intestino delgado, obtiveram-se as mesmas tendências observadas para o rúmenretículo, isto é, verificou-se menor peso com a utilização zeranol em associação ao colostro em relação ao uso do colostro sem zeranol ou do leite associado ao zeranol.

Quanto ao abomaso, verificou-se efeito da interação dieta líquida versus promotor de crescimento (Tab. 11), isto é, maior peso desse órgão com a utilização do colostro fermentado sem zeranol, quando comparado à dieta contendo leite.

A dieta com leite proporcionou crescimento adequado ao abomaso. Sabe-se que dietas líquidas resultam em abomasos mais desenvolvidos, porém seu volume cresce em proporção aproximada ao ganho de peso do corpo (Lucci, 1989) e à ingestão de matéria seca (Ribeiro et al., 2001b). Isso pode ser confirmado pelos dados das Tab. 5 e 11.

Tabela 11. Peso do abomaso ( $\mathrm{g}$ ) de bezerros, de acordo com a dieta líquida e o promotor de crescimento

\begin{tabular}{lcc}
\hline Dieta & Sem zeranol & Com zeranol \\
\hline Leite & $270 \mathrm{Ab}$ & $278 \mathrm{Aa}$ \\
Colostro fermentado & $319 \mathrm{Aa}$ & $264 \mathrm{Ba}$ \\
\hline
\end{tabular}

Valores seguidos por letras distintas maiúsculas na linha $\mathrm{e}$ minúsculas na coluna diferem entre si pelo teste $\mathrm{F}(\mathrm{P}<0,05)$.

Os animais que receberam óleo de soja apresentaram quantidades de gordura interna superior $(\mathrm{P}<0,01)$ aos não suplementados $(293 \mathrm{~g} \times 146 \mathrm{~g})$. Esse resultado indica que o suplemento energético (óleo) não foi depositado na estrutura corporal dos animais, mas sim como gordura interna.

\section{CONCLUSÕES}

O fornecimento de colostro fermentado promove maior ingestão de matéria seca em relação ao leite integral, o que resulta em desempenho semelhante entre os animais, não sendo necessária a utilização de óleo para suprir uma possível deficiência energética. A utilização do colostro fermentado garantiu boa qualidade de carcaça e o efeito do zeranol sobre o ganho de peso depende da dieta dos animais. 


\section{REFERÊNCIAS BIBLIOGRÁFICAS}

A CARNE que vem do rebanho leiteiro. Disponível em: <http://www.zebus.com.br>, Acesso em> 01 mar. 2003.

ALVES, P.A.M.; LIZIEIRE, R.S. Teste de um sucedâneo na produção de vitelos. Rev. Soc. Bras. Zootec., v.30, p.817-823, 2001.

ARGÜELlO, A.; CASTRO, N.; CAPOTE, J. et al. Effects of refrigeration, freezing-thawing and pasteurization on $\mathrm{IgG}$ goat colostrum preservation. Small Rum. Res., v.48, p.135-139, 2003.

BLUM, J.W.; HAMMON, H. Colostrum effects on the gastrointestinal tract, and on nutritional, endocrine and metabolic parameters in neonatal calves. Liv. Prod. Sci., v.66, p.151-159, 2000.

BORGES, A.S.; FEITOSA, F.L.F.; BENESI, F.J. et al. Influência da forma de administração e da quantidade fornecida de colostro sobre a concentração de proteína total e de suas frações eletroforéticas no soro sangüíneo de bezerros da raça Holandesa. Arq. Bras. Med. Vet. Zootec., v.53, p.629-634. 2001

BROWN, R.G. Implantes de zeranol. In: SYMPOSIUM ANABOLICS IN ANIMAL PRODUCTION, 1984, Paris. Anais... Paris, 1984. p.191-203.

CALDAS, F. Vitelo: opção de ganho na exploração leiteira. Balde Branco, n.461, p.3640, 2003.

CAMPOS, O. F.; LIZIEIRE, R.S.; RODRIGUES, A.A. et al. Colostro fermentado na alimentação de bezerros leiteiros. In: REUNIÃO ANUAL DA SOCIEDADE BRASILEIRA DE ZOOTECNIA, 22., Camboriú, 1985. Anais... Balneário de Camboriú, 1985. p.81.

CAMPOS, O.F. Estratégias de utilização do bezerro de rebanhos leiteiros para produção de carne. Coronel Pacheco, MG: EMBRAPA/CNPGL, 1994. 15 p.

CAMPOS, O.F.; LIZIEIRE, R.S. Alimentação de bovinos jovens. Cad. Téc. Esc. Vet. UFMG, n.14, 1995.

CAMPOS, O.F.; LIZIEIRE, R.S.; RODRIGUES, A.A. Colostro fermentado a temperatura ambiente, sem aditivos, para bezerros leiteiros. Rev. Soc. Bras. Zootec., v.15, p.338-339, 1986.

CHURCH, D.C. El ruminante: fisiologia digestiva y nutrición. Zaragoza, Espanha: Ed.Acribia, 1993. 641p.

EGAN, C.L.; WILSON, L.L.; DRAKE, T.R.et al. Effects of different doses of zeranol on growth, hemoglobin, and carcass traits in veal calves. J. Anim. Sci., v.71, p.1081-1087, 1993.

FOLEY, J.A.; OTTERBY, D.E. Availability, storage, treatment, composition and feeding value of surplus colostrum: A review. J. Dairy. Sci., v.61, p.1033-1060. 1978.

HALL, G.A.B. Zeranol, anabólico para ruminante: uma revisão. Rev. Soc. Bras. Zootec., v.6, p.86-105, 1977.

HANKINS, O.G.; HOWE, P.E. Estimation of the composition of beef carcass and cuts. Washington: USDA (Techinal Bulletin - USDA, 926). 1946.

JENNY, B.F.; HODGE, S.E.; O'DELL, G.D. et al. Influence of colostrum preservation and sodium bicarbonate on performance of dairy calves. J. Anim. Sci., v.67, p.313-318, 1984.

LIZIEIRE, R.S.; CAMPOS, O.F. Colostro fermentado com bicarbonato de sódio para bezerros leiteiros. Rev. Soc. Bras. Zootec., v.15, p.432-438, 1986.

LUCCI, C.L. Bovinos leiteiros jovens. São Paulo: Ed Nobel, 1989. 371p.

MATOS, L.L. Saiba como aproveitar o excesso de colostro. Balde Branco, n.367, p.29-30, 1996.

MORRIL, J.L. The calf: birth to 12 week. In: Van HORN, H.H.; WILCOX, C.J. (Eds.). Large dairy herd management, 1992. p.401-409

NARRO, L.A.; THOMAS, M.G.; SILVER, G.A. et al. Body composition, leptin, and the leptin receptor and their relationship to the growth hormone $(\mathrm{GH})$ axis in growing wethers treated with zeranol. Dom. Anim. Endocrinol., v. 24, p.243-255, 2003.

PLOG, J.; HUBER, J.T.; OXENDER, W. Growth, diarrhea, and gamma globulin of calves fed frozen and fermented colostrum. J. Dairy Sci., v.57, p.642, 1974 (Abstract).

RIBEIRO, T.R.; PEREIRA, J.C.; LEÃO, M.I. Tamanho de órgãos e vísceras de bezerros 
holandeses, para produção de vitelos, recebendo dietas com diferentes níveis de concentrado. Rev. Bras. Zootec., v.30, p.2163-2168, 2001b

RIBEIRO, T.R.; PEREIRA, J.C.; OLIVEIRA, M.V.M. Características da carcaça de bezerros holandeses para produção de vitelos recebendo dietas com diferentes níveis de concentrado. Rev. Bras. Zootec., v.30, p.2154-2162, 2001a.

RINDISIG, R.B. Sour colostrum dilutions compared to whole milk for calves. J. Dairy Sci., v.59, p.1293-1300, 1976.

ROCHA, E.O. Sistemas de aleitamento artificial, exigências nutricionais e características produtivas de bovinos de origem leiteira. 1997. 120f. Tese (Doutorado em Zootecnia) Universidade Federal de Viçosa, Viçosa, MG.

ROSA, G.O. Anabolizantes na produção animal. In: SIMPÓSIO NACIONAL DE REPRODUÇÃO ANIMAL, Belo Horizonte, 1988. Anais... Belo Horizonte, 1988. p.28-46.

SIGNORETTI, R.D. Substituição do milho e do farelo de soja pelo farelo de gérmen de milho na ração de bezerros desaleitados precocemente. 1994. 117f. Dissertação (Mestrado em
Zootecnia) - Universidade Federal de Viçosa, Viçosa, MG.

SISTEMA de análise estatísticas e genéticas SAEG. Viçosa: UFV, 1997.

SRINIVASAN, S.; XIONG, Y.L.; BLANCHARD, S.P. et al. Proximate, mineral and fatty acid composition of semimembranosus and cardiac muscles from grass- and grain-fed and zeranol-implanted cattle. Food Chem., v.63, p.543-547, 1998.

TEIXEIRA, J.C.; PEREZ, J.O.; MORON, I.R. Aproveitamento do macho leiteiro utilizando dietas à base de amirea 45s. Ciênc. Agrotec., v.24, p.203-207, 2000.

THOMAS, M.G.; CARROLL, J.A.; RAYMOND, S.R. et al. Transcriptional regulation of pituitary synthesis and secretion of growth hormone in growing weathers and the influence of zeranol on these mechanisms. Dom. Anim. Endocrinol., v.18 p.309-324, 2000.

URUAKPA, F.O.; ISMOND, M.A.H.; AKOBUNDU1, E.N.T. Colostrum and its benefits: a review. Nutr. Res., v.22, p.755-767, 2002. 